Tropical Journal of Pharmaceutical Research March 2016; 15 (3): 639-644

ISSN: 1596-5996 (print); 1596-9827 (electronic)

(C) Pharmacotherapy Group, Faculty of Pharmacy, University of Benin, Benin City, 300001 Nigeria.

All rights reserved.

Available online at http://www.tjpr.org

Original Research Article

http://dx.doi.org/10.4314/tjpr.v15i3.28

\title{
Culture of Safety among Nurses in a Tertiary Teaching Hospital in Saudi Arabia
}

\author{
Hisham Aljadhey ${ }^{1^{*}}$, Basmah Al-Babtain ${ }^{1}$, Mansour Adam Mahmoud ${ }^{1}$, Sinna \\ Alaqeel $^{2}$ and Yusuf Ahmed ${ }^{1}$ \\ ${ }^{1}$ Medication Safety Research Chair, ${ }^{2}$ College of Pharmacy, Clinical Pharmacy Department, King Saud University, Riyadh, Saudi \\ Arabia
}

*For correspondence: Email: haljadhey@ksu.edu.sa; Tel: +966 530039008

Received: 24 July 2015

Revised accepted: 9 February 2016

\begin{abstract}
Purpose: To assess the culture of safety among nurses in a tertiary teaching hospital in Saudi Arabia. Methods: A cross-sectional survey was conducted in King Khaled University Hospital in Riyadh, Saudi Arabia. A random sample of 492 nurses was included in the survey using a pre-validated instrument, Safety Attitudes Questionnaire (SAQ).

Results: Of the questionnaires given to 492 nurses, only 418 complete ones were returned, giving a response rate of $84.9 \%$. Most of the participants (354, 84.7\%) were staff nurses and the majority, 112 $(26.8 \%)$, had working experience of $\geq 20$ years. Job satisfaction was perceived as the most common dimension of culture of safety among nurse participants (92.7 \pm 14.6$)$ followed by working conditions (82.1 \pm 16.6$)$ and safety $(75.5 \pm 15.5)$ and teamwork $(75.5 \pm 16.7)$. Stress recognition $(41.9 \pm 25.2)$ and perception of management $(68.1 \pm 19.1)$ ranked as the least common dimensions of safety culture among study subjects. A significant difference in mean score was found between males and females for both working conditions $(p=0.035)$ and teamwork $(p=0.045)$. Significant differences were also observed in terms of job satisfaction dimension scores with regard to years of work experience $(p=$ 0.045). A significant differences was also observed in terms of stress recognition dimension scores in terms of years of work experience $(p=0.007)$.

Conclusion: Efforts are needed from healthcare authorities to increase nurses' perception of management and stress recognition in order to improve safety culture among nurses in Saudi Arabia.
\end{abstract}

Keywords: Nurses, Safety Attitudes Questionnaire (SAQ), Safety culture, Working conditions, Teamwork, Job satisfaction

Tropical Journal of Pharmaceutical Research is indexed by Science Citation Index (SciSearch), Scopus, International Pharmaceutical Abstract, Chemical Abstracts, Embase, Index Copernicus, EBSCO, African Index Medicus, JournalSeek, Journal Citation Reports/Science Edition, Directory of Open Access Journals (DOAJ), African Journal Online, Bioline International, Open-J-Gate and Pharmacy Abstracts

\section{INTRODUCTION}

Organizational culture is an important determinant of patient safety in healthcare organizations. There are several definitions of safety culture. The definition by The Advisory Committee on the Safety of Nuclear Installations (ACSNI) has been widely used in the context of patient safety in health care [1]. The ASCNI defined safety culture of an organization as "the product of individual and group values, attitudes, perceptions, competencies, and patterns of behavior that determine the commitment to, and the style and proficiency of, an organization's health and safety management."

Several tools have been developed to evaluate patient safety culture [2]. The majority of these tools evaluate five dimensions of patient safety culture: leadership, policies and procedures, 
staffing, communication, and reporting. Safety Attitude Questionnaire (SAQ) is one of the most widely used instruments to measure safety culture among different healthcare professionals due to its good psychometric properties [3]. SAQ measures six dimensions of safety culture: teamwork climate, safety climate, job satisfaction, stress recognition, perception of management, and working condition.

Research efforts in various countries have focused on the assessment of safety culture in healthcare organizations to improve the widespread deficits in patient safety [4-7]. The SAQ tool was used to design interventions that help to reduce adverse outcomes in an obstetric unit [8]. A study from Egypt measuring the culture of safety among nurses using the $S A Q$ instrument reported that nurses had a higher level of job satisfaction (mean score \pm standard deviation: $3.27 \pm 0.61$ ) and teamwork climate $(3.09 \pm 0.78)$, and a lower level of perception of management (2.16 \pm 0.59$)$ [7].

The Institute of Medicine report "To Err is Human" encouraged healthcare organizations to implement initiatives that aim to improve patient safety [9]. In Saudi Arabia several initiatives are being undertaken by healthcare organizations to improve the quality and safety of healthcare services. However, little is known about the perception and attitudes of healthcare professionals towards patient safety [6]. Nurses are at the frontline of patient care and play an important role in patient safety. Therefore, we aimed to assess the safety culture among nurses in a tertiary teaching hospital in Saudi Arabia.

\section{EXPERIMENTAL}

\section{Setting and sampling}

This was a cross-sectional study conducted in a tertiary teaching hospital in Riyadh, Saudi Arabia. The study included a random sample of nurses working in different inpatient departments in the hospital. Nurses were approached by the researcher during working hours and asked to participate in the study after explaining the aims of the survey. The institutional review board of the hospital approved the study.

\section{Study instrument}

The study instrument used was Safety Attitudes Questionnaire (SAQ). The questionnaire was developed and tested for validity and reliability by the Center of Excellence for Patient Safety
Research and Practice, University of Texas [3]. A pilot study was carried out on 10 nurses aimed at adapting the survey to fit the Saudi context and to verify that the items and questions were comprehensible and clear. The questionnaire language was maintained in English as it is the main language of communication in hospital settings in Saudi Arabia.

The SAQ assesses safety culture across six factors: teamwork climate, perceptions of management, safety climate, stress recognition, job satisfaction, and work environment. Teamwork climate is defined as perceived quality of collaboration between personnel; safety climate is the perception of a strong and proactive organizational commitment to safety; and job satisfaction is the positivity about work experience. Stress recognition is defined as the acknowledgement of how performance is influenced by stressors; perception of management is the approval of managerial action; and working condition is the perceived quality of the work environment and logistical support [3].

All responses were measured using a five-point Likert scale ( 1 = Disagree Strongly, 2 = Disagree Slightly, $3=$ Neutral, $4=$ Agree Slightly, $5=$ Agree Strongly). For each item in the scale, responses were converted to a 100 point scale as follows: $1=0,2=25,3=50,4=75$, and $5=$ 100. Items such as "in my work area, it is difficult to discuss errors" were reversely scored as follows: $1=100,2=75,3=50,4=25$, and $5=$ 0 , so that the higher the score, the more positive the attitude. Responses to each item in a particular scale were summed and divided by the number of all items in that scale to create scores from 0 to 100 for each scale. A score of $\geq 75 \%$ was considered positive.

\section{Data collection}

The survey was distributed to the nurses and each questionnaire was accompanied by a covering letter explaining the purpose of the survey. The letter stressed that the results of the survey would be anonymous and would be used for research purposes only. A verbal consent was obtained from all nurses. The nurses completed the surveys while they were in their work settings.

\section{Statistical analysis}

Descriptive statistics was done and data presented as counts and percentages, or mean \pm standard deviation. Independent t-test or oneway analysis of variance (ANOVA) was used to 
determine any differences between the mean scores of each safety culture dimension according to demographic characteristics as appropriate. Pearson's correlation coefficient was used to test for correlation between the dimensions of patient safety culture. The Statistical Package for Social Science (SPSS) version 20 (IBM SPSS Statistics for Windows, Version 20.0. Armonk, NY: IBM Corp) was used for data analysis.

\section{RESULTS}

The questionnaire was distributed to 492 nurses, however only 418 were completed and returned, giving a response rate of $84.9 \%$. The majority were female $394(94.3 \%)$ and in the $30-39$ years age group $(n=154,36.8 \%)$. Most 354 $(84.7 \%)$ of the participants were staff nurses and the majority $112(26.8 \%)$ had worked in their current position for at least 20 years (Table 1).

Table 1: Demographic characteristics of nurses $(\mathrm{N}=$ 418)

\begin{tabular}{lcc}
\hline Characteristics & Frequency & $\%$ \\
\hline Gender & & \\
Male & 24 & 5.7 \\
Female & 394 & 94.3 \\
Age group & & \\
<30 years & 98 & 23.4 \\
30-39 years & 154 & 36.8 \\
40-49 years & 85 & 20.3 \\
$\geq 50$ years & 81 & 19.4 \\
Organizational & & \\
role & & \\
Staff member & 354 & 84.7 \\
Supervisors and & 49 & 11.7 \\
seniors & & \\
Other & 15 & 3.6 \\
Years of work & & \\
experience & & \\
< 5 years & 59 & 14.1 \\
5-9 years & 90 & 21.5 \\
10-14 years & 77 & 18.4 \\
15-19 years & 80 & 19.1 \\
$\geq 20$ years & 112 & 26.8 \\
\hline
\end{tabular}

Table 2 illustrates nurses' perception of the six dimensions of safety culture and the overall safety culture dimension scores. Job satisfaction was perceived as the most common dimension among nurse participants $(92.7 \pm 14.6)$. This was followed by working condition (82.1 \pm 16.6), safety climate $(75.5 \pm 15.7)$ and teamwork climate (75.5 \pm 16.7) dimensions. Stress recognition (41.9 \pm 25.2$)$ and perception of management $(68.1 \pm 19.1)$ were perceived as the least common dimensions of patient safety culture among study subjects. The overall safety culture dimension mean score was $72.6 \pm 10.6$. The percentage of positive scores for each dimension and the overall dimension scores are also illustrated in Table 2.

Pearson's association coefficient revealed a strong positive correlation between overall safety culture dimensions score and all six dimensions of patient safety culture $(p<0.001$, Table 3$)$.

The association of demographic characteristics with the five dimensions of safety culture is illustrated in Table 4. Our results revealed a significant difference in teamwork climate mean score between females $(76.2 \pm 16.1)$ and males $(63.5 \pm 21.5)$. Females had a significantly higher teamwork climate mean score compared with male participants $(p=0.002)$. A significant difference was also observed for working condition mean score between males (75.3 \pm 17.6) and females $(82.5 \pm 16.4)(p=0.036)$. Significant differences were also observed in terms of job satisfaction dimension scores across years of experience $(p=0.045)$. A post-hoc analysis revealed that nurses who had a work experience of 20 years or more $(93.7 \pm 13.7)$ had a significantly higher mean score of job satisfaction. A significant differences were also observed in term of stress recognition dimension scores among years of experience $(p=0.007)$. A post-hoc analysis revealed that nurses who had

Table 2: Mean score and \% positive score for all safety culture dimensions

\begin{tabular}{lll}
\hline Items/Total score & Mean (SD) & \% Positive score \\
\hline Safety climate & $75.5(15.5)$ & 59.0 \\
Teamwork climate & $75.5(16.7)$ & 62.4 \\
Job satisfaction & $92.7(14.6)$ & 92.6 \\
Stress recognition & $41.9(25.2)$ & 17.7 \\
Perception of management & $68.1(19.1)$ & 44.2 \\
Working conditions & $82.1(16.6)$ & 77.2 \\
Overall safety culture & $72.6(10.6)$ & 46.7 \\
\hline
\end{tabular}


Table 3: Correlation between safety culture dimensions as perceived by participating nurses

\begin{tabular}{|c|c|c|c|c|c|c|c|}
\hline & & $\begin{array}{l}\text { Safety } \\
\text { Climate }\end{array}$ & $\begin{array}{c}\text { Teamwork } \\
\text { Climate }\end{array}$ & $\begin{array}{c}\text { Job } \\
\text { Satisfaction }\end{array}$ & $\begin{array}{c}\text { Stress } \\
\text { Recognition }\end{array}$ & $\begin{array}{c}\text { Perception } \\
\text { of } \\
\text { Management }\end{array}$ & $\begin{array}{l}\text { Working } \\
\text { Conditions }\end{array}$ \\
\hline \multicolumn{8}{|l|}{ Safety } \\
\hline \multicolumn{8}{|l|}{ Climate } \\
\hline \multirow{2}{*}{$\begin{array}{l}\text { Teamwork } \\
\text { Climate }\end{array}$} & $R$ & $0.426^{\pi x}$ & & & & & \\
\hline & $P$-value & 0.000 & & & & & \\
\hline \multirow{2}{*}{$\begin{array}{l}\text { Job } \\
\text { Satisfaction }\end{array}$} & $R$ & $0.286^{\star *}$ & $0.388^{\star *}$ & & & & \\
\hline & $P$-value & 0.000 & 0.000 & & & & \\
\hline \multirow{2}{*}{$\begin{array}{l}\text { Stress } \\
\text { Recognition }\end{array}$} & $R$ & 0.069 & $0.165^{\star *}$ & -0.014 & & & \\
\hline & $P$-value & 0.126 & 0.000 & 0.755 & & & \\
\hline \multirow{2}{*}{$\begin{array}{l}\text { Perception of } \\
\text { Management }\end{array}$} & $R$ & $0.229^{* *}$ & $0.204^{\star *}$ & $0.267^{* *}$ & -0.016 & & \\
\hline & $P$-value & 0.000 & 0.000 & 0.000 & 0.730 & & \\
\hline \multirow{2}{*}{$\begin{array}{l}\text { Working } \\
\text { Conditions }\end{array}$} & $R$ & $0.383^{* *}$ & $0.358^{* *}$ & $0.446^{* *}$ & $0.094^{*}$ & $0.394^{* *}$ & \\
\hline & $P$-value & 0.000 & 0.000 & 0.000 & 0.038 & 0.000 & \\
\hline \multirow{2}{*}{$\begin{array}{l}\text { Overall safety } \\
\text { culture } \\
\text { dimensions }\end{array}$} & $R$ & $0.616^{\star *}$ & $0.675^{\star *}$ & $0.587^{\star *}$ & $0.479^{* *}$ & $0.563^{\star *}$ & $0.699^{* *}$ \\
\hline & $P$-value & 0.000 & 0.000 & 0.000 & 0.000 & 0.000 & 0.000 \\
\hline
\end{tabular}

$\mathrm{R}=$ Pearson correlation, ${ }^{* *}$ correlation is significant at the level $0.001,{ }^{*}$ correlation is significant at the level 0.05

a work experience of $10-14$ years or more $(93.7$ $\pm 13.7)$ had a significantly higher mean score of stress recognition $(p=0.001)$.

\section{DISCUSSION}

In the current study we assessed the safety culture among nurses in a teaching hospital in Saudi Arabia. A total of 492 nurses participated in this study. The study population mostly included female professionals confirming the characteristics of the profession. Nurses showed positive perception towards four dimensions of safety culture: job satisfaction, working condition, safety climate, and teamwork climate. Negative perception was reported among nurses in two dimensions of safety culture: the perception of management, and stress recognition.

Similar to our finding several studies support that nurses are generally satisfied with their job [1012. This is an encouraging finding for healthcare organizations as job satisfaction has previously been found to be positively associated with organizational commitment and organizational support among nurses [10-12]. In addition, improving the satisfaction at work has been reported to result into an increase in the job performance and, consequently, improve the quality of patient safety $[13,14]$. Interestingly, the job satisfaction increased with the increase in the years of experience in this study. Similarly, nurses' job satisfaction has been previously reported to significantly reduce staff turnover [15] and intent to leave the job [16]. In addition, similar to our findings, job satisfaction has been previously reported to be positively associated with teamwork in other studies $[17,18]$.

Patient safety is the key issue for any healthcare organization and nurses are an integral part of any hospital; hence understanding the safety culture among nurses in a Saudi hospital is very important for improving patient safety. The study nurses were employees of a teaching hospital and previous studies have shown that nurses working in a teaching hospital have high organizational learning culture $[19,20]$. Therefore, there is a need to emphasis on nursing continuous education programs to keep them upto-date with current advances in nursing practice and encourage the application of safety knowledge in the daily nursing practice [21].

Nurses in the current study have shown low perception of management. Hospital management should utilize the high job satisfaction of nurses to increase their perception of management. Changes in patient safety culture can be implemented by moving from a culture of blame to a culture of safety. Interventions suggested to improve nurses' perception of management include but are not limited to, effective leadership, continuous 
Table 4: Association of mean scores of each safety culture dimension according to demographic characteristics

\begin{tabular}{|c|c|c|c|c|c|c|c|c|c|c|c|c|c|c|}
\hline & $\begin{array}{l}\text { Mean(SD) } \\
\text { Safety } \\
\text { Climate }\end{array}$ & $\mathbf{P}$ & $\begin{array}{l}\text { Mean(SD) } \\
\text { Teamwork } \\
\text { Climate }\end{array}$ & $\mathbf{P}$ & $\begin{array}{l}\text { Mean(SD) } \\
\text { Job } \\
\text { Satisfaction }\end{array}$ & $\mathbf{P}$ & $\begin{array}{l}\text { Mean(SD) } \\
\text { Stress } \\
\text { Recognition }\end{array}$ & $\mathbf{P}$ & $\begin{array}{l}\text { Mean(SD) } \\
\text { Perception } \\
\text { of } \\
\text { Management }\end{array}$ & $\mathbf{P}$ & $\begin{array}{l}\text { Mean(SD) } \\
\text { Working } \\
\text { Conditions }\end{array}$ & $\mathbf{P}$ & $\begin{array}{l}\text { Overall } \\
\text { dimensions }\end{array}$ & $\mathbf{P}$ \\
\hline Gender & & & & & & & & & & & & & & \\
\hline Female & $\begin{array}{l}75.8 \\
(15.3)\end{array}$ & $\begin{array}{l}0.14 \\
9\end{array}$ & $76.2(16.1)$ & 0.002 & 93.1(13.9) & $\begin{array}{l}0.08 \\
9\end{array}$ & $41.8(25.2)$ & $\begin{array}{l}0.89 \\
8\end{array}$ & $68.4(18.8)$ & $\begin{array}{l}0.17 \\
4\end{array}$ & $82.5(16.4)$ & $\begin{array}{l}0.03 \\
6\end{array}$ & $73.1(10.2)$ & $\begin{array}{l}0.07 \\
8\end{array}$ \\
\hline $\begin{array}{l}\text { Male } \\
\text { Age group }\end{array}$ & $70.1(17.7)$ & & $63.5(21.5)$ & & $86.4(22.7)$ & & $42(26.2)$ & & $62.8(22.7)$ & & $75.3(17.6)$ & & $66.7(15.4)$ & \\
\hline$<30$ years & $74.6(15.4)$ & $\begin{array}{l}0.80 \\
4\end{array}$ & 71.6(18.9) & 0.106 & $91.5(15.1)$ & $\begin{array}{l}0.22 \\
6\end{array}$ & $43.7(26.5)$ & $\begin{array}{l}0.10 \\
3\end{array}$ & $67.1(21.0)$ & $\begin{array}{l}0.12 \\
9\end{array}$ & 83.1(17.3) & $\begin{array}{l}0.46 \\
3\end{array}$ & $71.9(11.9)$ & $\begin{array}{l}0.92 \\
2\end{array}$ \\
\hline 30-39 years & $76.0(16.4)$ & & $77.5(15.6)$ & & $92.1(14.7)$ & & $44.7(25.3)$ & & $66.8(18.9)$ & & $80.3(17.8)$ & & $72.9(10.7)$ & \\
\hline 40-49 years & $74.7(15.5)$ & & $75.9(16.7)$ & & $93.2(14.6)$ & & $36.7(23.7)$ & & $68.0(17.9)$ & & $82.2(15.8)$ & & $71.8(11.0)$ & \\
\hline $\begin{array}{l}\geq 50 \text { years } \\
\text { Organizational } \\
\text { Role }\end{array}$ & 76.3(13.8) & & 75.8(15.3) & & $94.4(13.6)$ & & $39.6(24.5)$ & & $71.8(17.9)$ & & $83.9(13.6)$ & & $73.6(8.2)$ & \\
\hline Staff member & $72.4(10.8)$ & $\begin{array}{l}0.80 \\
4\end{array}$ & $75.6(17.1)$ & 0.106 & $92.9(14.3)$ & $\begin{array}{l}0.22 \\
6\end{array}$ & $42.2(26.1)$ & $\begin{array}{l}0.10 \\
3\end{array}$ & 67.6(19.2) & $\begin{array}{l}0.12 \\
9\end{array}$ & $81.5(16.7)$ & $\begin{array}{l}0.46 \\
3\end{array}$ & $72.6(10.1)$ & $\begin{array}{l}0.92 \\
2\end{array}$ \\
\hline $\begin{array}{l}\text { Supervisor and } \\
\text { seniors }\end{array}$ & $73.0(8.5)$ & & $76.8(14.5)$ & & $92.9(14.9)$ & & $38.1(23.7)$ & & $69.3(15.7)$ & & $85.3(13.1)$ & & $73.1(8.2)$ & \\
\hline $\begin{array}{l}\text { Other } \\
\text { Years of } \\
\text { experience }\end{array}$ & $75.9(12.0)$ & & $77.1(21.1)$ & & $96.8(5.5)$ & & $46.8(22.5)$ & & $72.3(24.1)$ & & $86.4(13.9)$ & & $75.8(11.6)$ & \\
\hline $\begin{array}{l}\text { Less than } 5 \\
\text { years }\end{array}$ & $\begin{array}{l}76.6 \\
(14.1)\end{array}$ & $\begin{array}{l}0.69 \\
5\end{array}$ & $74.0(18.6)$ & 0.732 & $88.3(16.3)$ & $\begin{array}{l}0.04 \\
5\end{array}$ & $44.2(29.1)$ & $\begin{array}{l}0.00 \\
7\end{array}$ & $66.9(21.4)$ & $\begin{array}{l}0.65 \\
2\end{array}$ & $79.2(17.3)$ & $\begin{array}{l}0.70 \\
2\end{array}$ & $71.5(12.4)$ & $\begin{array}{l}0.39 \\
4\end{array}$ \\
\hline $5-9$ years & $73.5(17.2)$ & & 73.7(19.9) & & $92.7(16.1)$ & & $40.0(25.4)$ & & 67.9(19.2) & & $82.5(17.2)$ & & $71.7(10.8)$ & \\
\hline $10-14$ years & $77.1(16.1)$ & & $76.6(14.3)$ & & $93.6(12.6)$ & & $48.4(25.8)$ & & $66.4(18.7)$ & & $82.3(16.6)$ & & $74.1(10.8)$ & \\
\hline $15-19$ years & $75.4(14.7)$ & & $77.9(15.6)$ & & $93.2(14.3)$ & & $44.7(23 . .8)$ & & $68.4(19.3)$ & & $82.6(16.7)$ & & $73.7(10.7)$ & \\
\hline 20 years or more & 75.3(14.8) & & $75.3(15.2)$ & & $93.7(13.5)$ & & $35.5(22.3)$ & & $69.7(17.8)$ & & $82.5(15.6)$ & & $72.0(9.2)$ & \\
\hline
\end{tabular}


education and training programs, and ongoing measurement of progress. These interventions should be tested in Saudi Arabia.

\section{Limitations of the study}

The study has some limitations. The data included nurses from one academic practice setting and therefore, the results may not be generalizable to nurses working in other hospitals in Saudi Arabia. When the study was conducted, the hospital was in the planning and preparation stage for accreditation and therefore this might have positively skewed nurses' responses to our survey.

\section{CONCLUSION}

Efforts are needed from healthcare authorities to increase nurses' awareness about various aspects of safety culture. Further studies are also needed to study safety culture in various hospitals and among different healthcare professionals. Patient safety is the goal of any healthcare organization. Therefore, a blame-free culture should be promoted by top healthcare management authorities to encourage error reporting and design future prevention strategies.

\section{ACKNOWLEDGEMENT}

The authors thank all nurses who participated in this study. The study was partially funded by the Medication Safety Research Chair at King Saud University.

\section{REFERENCES}

1. Advisory Committee on the Safety of Nuclear Installations (ACSNI) Study Group on Human Factor. Third Report: Organizing for Safety, 1993.

2. Colla JB, Bracken AC, Kinney $L M$, Weeks WB. Measuring patient safety climate: a review of surveys. Qual Saf Health Care 2005; 14: 364-366.

3. Sexton JB, Helmreich RL, Neilands TB, Rowan K, Vella $K$, Boyden J, Roberts PR, Thomas EJ: The safety attitudes Questionnaire: psychometric properties, benchmarking data, and emerging research. BMC Health Services Research 2006; 6: 44.

4. Nordén-Hägg A, Sexton JB, Kälvemark-Sporrong S, Ring L, Kettis-Lindblad A. Assessing safety culture in pharmacies: the psychometric validation of the Safety Attitudes Questionnaire (SAQ) in a national sample of community pharmacies in Sweden. BMC Clin Pharmacol 2010; 10: 8.

5. El-Jardali $F$, Jaafar M, Dimassi $H$, Jamal $D$, Hamdan $R$. The current state of patient safety culture in Lebanese hospitals: a study at baseline. Int J Qual Health Care 2010; 22: 386-395.
6. Alahmadi HA. Assessment of patient safety culture in Saudi Arabian hospitals. Qual Saf Health Care 2010; 19: e17.

7. Abdou H, Saber KA. Baseline Assessment of Patient Safety Culture among Nurses at Student University Hospital. World J Med Sci 2011; 6: 17-26.

8. Pettker CM, Thung SF, Norwitz ER, Buhimschi CS, Raab CA, Copel JA, Kuczynski E, Lockwood CJ, Funai EF. Impact of a comprehensive patient safety strategy on obstetric adverse events. Am J Obstet Gynecol 2009; 200: 492. e1-8.

9. Kohn L, Corrigan J, Donaldson M. To err is human: building a safer health system, Institute of Medicine Report. Washington, DC: National Academy Press, 1999.

10. Al-Hussami M. A Study of Nurses' Job Satisfaction: The Relationship to Organizational Commitment, Perceived Organizational Support, Transactional Leadership, Transformational Leadership, and Level of Education. Euro J Sci Res 2008; 22: 286-295

11. Al-Aameri AS. Job satisfaction and organizational commitment for nurses. Saudi Med J 2000; 21: 231-235.

12. Wu L, Norman I. An investigation of job satisfaction, organizational commitment and role conflict and ambiguity in a sample of Chinese undergraduate nursing students. Nurse Educ Today 2006; 26: 304-314.

13. Hayes LJ, O'Brien-Pallas L, Duffield C, Shamian J, Buchan J, Hughes F, Spence Laschinger HK, North N, Stone PW. Nurse turnover: a literature review. Int $\mathrm{J}$ Nursing Studies 2006; 43: 237-263.

14. Wisniewski AM, Erdley WS, Singh R, Servoss TJ, Naughton BJ, Singh G. Assessment of Safety Attitudes in a Skilled Nursing Facility. Geriatr Nurs. 2007; 28: 126136.

15. Zakari NMA. Attitude of academic ambulatory nurses toward patient safety culture in Saudi Arabia. Life Scienc J. 2011; 8: 230-237.

16. Brewer C, Kovner C, Green W, Cheng Y. Predictors of $R N s_{-}$intent to work and work decisions 1 year later in a U.S. national sample. Int J Nursing Studies 2009; 46: 940-956.

17. Rafferty AM, Ball J, Aiken LH. Are teamwork and professional autonomy compatible, and do they result in improved hospital care? Quality in Health Care 200; 10: 32-37.

18. Kalisch BJ, Lee $H$, Rochman M. Nursing staff teamwork and job satisfaction. J Nursing Manag 2010; 18: 938947

19. Hatam N, Keshtkar V, Forouzan F, Bastani P. Patient safety culture status in teaching hospitals: a case of Shiraz University of Medical Sciences. Middle East J Sci Res. 2012; 12, 970-975

20. Tabibi J, Nasiripour A, Maleki M, Raessi P, Mahmmoudi M, Azimi L. Survey of employees' safety attitude in a teaching hospital Tehran Iran Occup Hea. 2010; 7, 2531

Trop J Pharm Res, March 2016; 15(3): 644 
Al-Babtain et al

21. Vaismoradi $M$, Salsali $M$, Marck P. Patient safety: nursing students' perspectives and the role of nursing education to provide safe care. Int Nurs Rev. 2011; 58 :434-442. 